\title{
Conceptualizing urban water security in an urbanizing world
}

Patricia Romero-Lankao, PhD, Senior Scientist, Lead of Urban Futures, NCAR, prlankao@ucar.edu

Daniel M. Gnatz, MnS Institute for Sustainable Urban Transformations, ISUT, gnatz@isut.org

\begin{abstract}
In this paper we review literature and suggest a framework to examine and measure urban water security as it interacts with urbanization and urban-regional systems. We develop a comprehensive framework to start bridging that gap. In this framework, urban water security is shaped by five interacting social and environmental domains. These are Socio-demographic, Economic, Technological, Ecological, and Governance (SETEG). We suggest a few indicators and aggregation methods that can shed light on the multidimensional and interconnected nature of urban water security, and illuminate different levels of influence among the five SETEG domains. By improving the selection of indicators for the multiple SETEG domains and interactions creating urban water security (or insecurity), combined approaches such as the one outlined above might help move a scattered array of water security goals towards the creation of informed, cohesive and relevant policy interventions.
\end{abstract}

\section{Introduction}

While the concept of water security has received increased interest recently[1*], relatively few scholars and practitioners have engaged with urban water security. This is not surprising given that agriculture has historically been the main water user; however, this trend is starting to change. Urban areas are increasingly shaping water security as they grapple with the sustainable availability of water and navigate the barriers and options involved in protecting people and ecosystems against water-borne stresses and water-related hazards [2]. Urbanization, itself, can, and often does, create many of these obstacles and options. For instance, it can exacerbate competition for water and deplete aquifers and water bodies [3], but it also has the potential to create the conditions for a sustainable enhancement of water security. Though much of this potential remains untapped and unexplored.

Climate and environmental change are also projected to affect water availability and heighten stress on water supplies by increasing the evaporation of surface water and altering the timing and dynamics of snowmelt, monsoons, rainfall and other hydrological processes [4]. Such changes have a high probability of affecting the replenishment of reservoirs and creating negative impacts to urban areas, such as floods and droughts [5,6]. An interaction between urbanization and environmental change is affecting water security in unprecedented ways that will challenge urban actors to find opportunities for innovative and transformative actions and responses. To be successful, urban and regional water managers and actors will need tools that can help them assess the challenges posed to water security by their unique urbanization pathways. They will also need metrics to determine the effectiveness and sustainability of any actions they design to enhance water security. 
In this paper, we will examine the dynamic links between urbanization, urban areas and water security and suggest some ways to respond cohesively to these challenges. Building on the findings of existing literature, we will suggest a framework to approach and assess urban water security. We hypothesize that urban water security is embedded in (and shaped by) interactions between urbanization, urban-regional systems, regimes and users, and a complex resource. These interactions take place within a broader context of drivers such as globalization, climate change, global urbanization, environmental degradation and shifts in international governance regimes (see Fig. 1).We discuss existing frameworks, metrics and aggregation methods, built upon national level models and metrics, which, we suggest, can be used to measure urban water security. This approach attempts to bridge the gap between scholarship and methods that focus on urban area dynamics with those that study regional, national and global views but ignore the local urban area, where any change must be actualized. Such approaches can help move scattershot urban-regional water security goals towards more cohesive and policy relevant narratives and interventions.

\section{Conceptualizing urbanization, urban areas and water security}

Before exploring the influence of urbanization and urban areas, with their unique place-based socioecological features, in shaping water security, we will briefly consider the definitions of 'urbanization', 'urban', and 'water security.' Pathways of urbanization and the urban areas they produce belong to a set of worldwide, mega-phenomena that are profoundly altering the relationship between human beings and the environment, while affecting water security in complex ways and at alarming rates. Yet, paradoxically, little agreement exists among scholars and communities of practice about the definition of urban and what makes a population or place urban [7-9]. We define urban areas as socioecological systems comprised of five interacting (SETEG) development domains (see Fig. 1) [10], which also interact with environmental dynamics. These domains are: (a) Socio-demographic, e.g., living in hazard-prone areas based on lifestyles (aesthetic desirability of location) or lack of options; (b) Economic, affecting differences in wealth creation and access to water, and to assets and options to respond to climate risks; (c) Technological, defining the possibilities to introduce high efficiency water infrastructure or flood protection measures more sustainably; (d) $\underline{E}$ cological, affecting an area's water and land endowments and susceptibility to hazards, and (e) Governance, shaping patterns of urban growth, land use regulations, water management and use, and proactive or reactive water risk mitigation and adaptation responses.

We define urbanization as an array of interconnected changes (transitions) that determine how humans interact with each other, and with the environment, to produce an urban area [9,11]. These transitions, which are key to water security issues, include: an increased number of people living in relatively compact areas; changes in lifestyle and culture; economic shifts from primary activities, such as agriculture or mineral extraction to manufacturing and services; land use changes associated with the growth of urban built-environments and infrastructures; and the transformation of ecosystems and hydrological systems associated with these changes.

Urbanization and urban areas directly and indirectly shape water security. Because of the large changes in economic growth, population structure, social practices 12 and lifestyles, land use and 
the built environment that they imply, urban processes are an increasingly important source of competing demands on water resources, changes in the hydrological cycle and land and habitat fragmentation dynamics [13]. Differences in land use, quality and function determine water availability and hazard risk in various ways. For instance, changes in vegetation cover affect infiltration and evapotranspiration dynamics, thereby influencing the risk of floods, and rainfall triggered landslides [14,15]. As a result of changes in the physical characteristics of the land surface associated with land use (e.g., albedo, surface absorption and runoff), the amount and effects of precipitation can be enhanced or reduced depending on climate regime, water use, geographic location and regional and global patterns.

Water security studies have also been subject to differences in definition and scope [1], with some scholars targeting specific issues of scarcity and stress [16], water supply systems security [17*], instability, or conflict and national security [18], while others (such as those associated with the World Water Forum) are developing more integrated approaches considering issues of access, affordability, human need and ecosystem wellbeing [1*]. We define urban water security as the capacity of urban water actors to maintain a sustainable availability of adequate quantities and quality of water, to foster resilient urban communities and ecosystems in the face of uncertain global change $\left[19^{*}, 20\right]$.

It is important to unpack two key components of this definition: sustainable availability of adequate quantities of water, and resilient urban areas and ecosystems. The notion of a sustainable availability of water necessitates an examination of the interactions and tensions between the three pillars of urban sustainability: economic development, social equity and environmental protection [21]. Fostering water security entails planning, policy and action seeking to bring urban-regional economies and local land development into closer alignment with (a) the limits regional basins pose to the provision of water and the needed environmental protection of regional basins and ecosystems; and (b) the social equity goal of providing every person with equal access to adequate amounts of safe, affordable water to assure life, life-quality and livelihood. At the same time, the notion of urban and regional resilience requires an understanding of the vulnerability of urban-regional water users (i.e., households and farmers) and ecosystems to water related hazards. Promoting urban water resilience will involve planning, policy and action to align urban sustainability and sustainable urban livelihoods with the enhancement of the capacity of water users and managers to perceive water relevant risks and effectively respond. Two aspects of urban water security, sustainability and resilience, can overlap, conflict, undermine or support each other. For instance, ecosystems managed for water provision, often lead to unintended consequences such as increased flood hazard risk. Reduced water availability during droughts can affect sustainability goals such as food supplies and energy provision [22]. Therefore, it is important to evaluate the interactions, tradeoffs and synergies between them.

In our conceptual framing, urbanization gives rise to urban areas and management regimes with context-specific SETEG features, with implications for urban water security affecting both sustainability and resilience. Consideration of these two aspects of urban water security shapes urban efforts to (a) enhance sustainable water availability, flood regulation, and recreation, and (b) manage the risks from droughts, floods and other hazards (resilience).Within the water use arena, urban areas function as networks of actors (e.g., water users, community leaders and 
managers) utilizing and transforming interconnected metabolic processes, technologies, infrastructures, and built-environments. This function fulfils an integral part of a broader project of urbanization: the social construction and transformation of ecosystems' structure, function and services to meet human need and purpose. Infrastructures are not only politically constructed and regulated, but they are also key components of urban metabolism shaping water use and settlement patterns, transforming the hydrological cycle, conveying water and wastewater, and mitigating or catalyzing risks differentially at different scales and localities [21-24]. Urbanregional water and risk management regimes shape, and are shaped by, the behavior and relationships of urban actors, with differing levels of power and resources, through legitimation, domination and signification structures [23-25].

While urban water regimes are dynamically stable, they are constantly subject to three sets of internal and external, local and regional drivers and pressures that can lead to their destabilization and transformation. Some of these drivers and pressures are: innovations, or proactive changes such as new technologies, social experiments, and governmental or grassroots initiatives; conflict and contestation of actions around access to, use of or redistribution of water, with resulting social and environmental implications (e.g., on water quality and availability, social inequality, livelihoods); and environmental impacts and triggers in the form of water depletion and scarcity, disasters, or changes in risk tolerance resulting from shifts in economic, cultural and or political dynamics [26,27]. These local and regional drivers interact with a broader set of global changes and pressures (see Fig.1). In the next section, we will build on this framework, and on scholarship examining water security in general, to suggest metrics and aggregation methods that can be used for urban water security assessment and enhancement.

\section{Measuring urban water security, options and challenges}

Designing effective metrics and indicators is a critical step in determining priorities among water managers and enhancing capacity for users. While current measurement and assessment tools may help create fair and effective interventions to foster water security within and across urbanareas and regions, a complex problem remains. Even with the right indicators of urban water security in place, meaningful conclusions will be elusive until their relative influences are known. One major reason that we have a lack of clarity here is that scholarship has mainly focused on countries, regions and largescale watersheds [2,28], and (with a few exceptions) $\left[17^{*}\right]$, little attention has been paid to the water security of urban areas and local to regional watersheds.

In measuring urban water security, the choice of indicators depends on the theoretical approach used. Because urbanization, urban areas and water security are multivariate and multifaceted, with differences often dependent on disciplinary perspective, definition and scope (see section 2), a range of different methods can be used to quantitatively characterize the relative importance of indicators. For instance, examples from scholarship focused on water scarcity as a proxy for urban water security (i.e., water quantity and availability), often combine two indices. The first index, water stress, includes a ratio of the current, urban-regional water withdrawal to the availability of water resources in order to estimate apparent scarcity based on regional, demanddriven use. Water shortage or water crowding, the second index, estimates urban-regional, population driven water scarcity by measuring the number of urban households and other water 
users that have to share each unit of a regional water resource $[29,30]$. Other scholars have applied more integrated tools to measure water scarcity. For example, the Water Poverty Index connects physical indicators of water availability with socioeconomic indicators of unequal development. These indicators include access to water, water quantity, quality and variability, water uses, capacity for water management, and environmental quality. [31,32]. However, in order to plan for future water security, attention must also be focused on water basins. To respond to this gap, some scholars have suggested the use of a pressure-response function to measure pressures and policy in watershed management responses. Such approaches have been used to develop a Watershed Sustainability Index [33], incorporating parameters from hydrology (water quality and quantity), the environment (vegetation), life quality (development) and basin policy (institutional capacity). However, these approaches generally stop short of incorporating the local drivers and dynamics of urban water security.

By embedding existing metrics within our integrative and broad framing of urban water security, we can better measure and represent the complexity of security in urban areas and their regions. This framework has the necessary elements to provide direction toward a desired end state that considers both urban area water security and water basin sustainability. It can help to determine key thresholds below which urban users become water insecure or beyond which water systems are unsustainable and households and ecosystems become vulnerable. In this context, urbanregional populations and decision makers can achieve water security only if they can successfully manage the elements of the sustainable availability of water and balance ecosystem and urban resilience (see section 2). We suggest that this can be achieved through fostering management regimes that incorporate the five SETEG development domains by:

- Fairly satisfying urban-regional users water and sanitation needs, and building resilient communities and ecosystems that can sustainably adapt to change (ㅇoiodemographic);

- Fostering vibrant urban-regional economies in industry, agriculture and energy (Economic);

- Designing and constructing (or upgrading existing) water supply and sanitation infrastructure to be multifunctional, redundant, modular (adaptable) and "safe to fail" [34] (Technological);

- Maintaining or restoring healthy regional water bodies and ecosystems (Ecological);

- Fostering water institutions (Governance) able to balance their inherently conservative and reactive natures with the need to be adaptive, fair and flexible [35-37].

A scoping diagram can be used as a vehicle for specification of indicators of urban water security (see Fig. 2). The ring nearest the center parses urban water security into its five SETEG domains; and the outer ring includes the measurements, or indicators [37]. Table 1 offers a list of suggested indicators based on the review of existing literature.

One of the most common approaches used to derive composite measures of urban water security has been to aggregate indicators into indices $\left[19^{*}, 38\right]$, many of which assume that all indicators 
should be weighted equally. While this method has the virtue of simplicity, it often creates overgeneralization. A common practice to overcome this limitation has been the use of principal components analysis (PCA) to aggregate and reduce the variables describing a phenomenon [e.g., 38,39]. However, although this method attempts to take account of relative values and to simplify the multivariate structure of the data, it runs the risk of omitting important dimensions of urban water security.

Scholars have pointed to the need of critically and constructively embracing subjectivity and uncertainty in many processes involved in the construction of indices. Such processes include: the theoretical assumptions that form the basis for any selection of determinants or framing of relationships between drivers and outcomes; the selection of indicators, which may or may not be sufficient to describe the dynamics of urban water security; the weights assigned to each indicator; and the ranking of observation units into security categories [40-42].

Throughout the indicator selection and index construction process, several procedures may be applied to deal with subjectivity and uncertainty that will inevitably spring from any collaboration between researchers, urban-regional experts and populations. For example, in the selection, weighting and aggregation of indicators, experiential scalograms can be used to examine water security as experienced by households [43*]. In another example, Analytic Hierarchy Process (ANH), a multicriteria decision analysis tool used to weight indicators, has been combined by some researches with fuzzy logic to assign indices to category groups [4042]. While ANH offers clear steps to weight indicators based on expert knowledge, theory and empirical research, fuzzy logic is useful to address the imprecision, uncertainty and complexity associated with multifaceted phenomena such as urban water security.

\section{Conclusions}

In order to create urban water security and sustainability, it will be necessary to bridge the gap between scholarship and methods focused on urban dynamics with those that examine water security. This will necessitate integrative approaches that consider global, regional and local dimensions. The framework we have suggested in this paper includes context-specific SETEG features of urban areas and management regimes, which have implications for urban water security affecting both sustainability and resilience. These SETEG domains may conflict or reinforce one another, but attention to their interactions, tradeoffs and synergies will be necessary to create true urban water security.

Combined approach to indicators and aggregation methods offer promise to shed light on the multidimensional and interconnected nature of attributes of urban water security and to illuminate different levels of influence among the five SETEG development dimensions. We have given one example of a combined approach, using an Analytic Hierarchy Process to weight indicators for indices, based on expert knowledge and literature reviews and then using fuzzy logic to allow for uncertainty in the categorization of these indices.

By improving the selection of indicators for the multiple SETEG dimensions and interactions creating urban water security (or insecurity), combined approaches such as the one outlined above might help move a scattered array of water security goals towards the creation of informed, cohesive and relevant policy interventions. We are not attempting to promote one particular methodology, however. Many other methods might also be used to undertake the 
daunting task of capturing the multidimensionality of urban water security, e.g., decile ratios and thresholding [see 44,45]. In order to move towards better solutions, we will need more studies that use combined approaches to examine the dynamic, multidimensional interactions and interconnections of water security.

Acknowledgements: The work of Patricia Romero-Lankao is supported by the National Science Foundation (NSF). Any opinions, findings and conclusions, recommendations or omissions expressed are those of the author and do not necessarily reflect the views of NSF. We want to thank an anonymous reviewer for her helpful comments.

\section{References}

1. * Cook, C. \& Bakker, K. Water security: Debating an emerging paradigm. Glob. Environ. Change 22, 94-102 (2012).

This is a systematic review of the concept of water security. It shows that the use of the term has increased significantly in recent years, across multiple disciplines. The paper compares definitions of, and analytical approaches to, water security across disciplinary domains.

2. Bogardi, J. J. et al. Water security for a planet under pressure: interconnected challenges of a changing world call for sustainable solutions. Curr. Opin. Environ. Sustain. 4, 35-43 (2012).

3. McPhee, J. et al. Water Security in Chile's Cities: Advances and Pending Challenges. Chall. Am. 148 (2015).

4. Arnbjerg-Nielsen, K. et al. Impacts of climate change on rainfall extremes and urban drainage systems: a review. Water Sci. Technol. 68, 16-28 (2013).

5. Allan, C., Xia, J. \& Pahl-Wostl, C. Climate change and water security: challenges for adaptive water management. Curr. Opin. Environ. Sustain. 5, 625-632 (2013).

6. Taylor, R. G. et al. Ground water and climate change. Nat. Clim. Change 3, 322-329 (2013).

7. Galea, S. Urbanization, urbanicity, and health. J. Urban Health 79, S1-S12 (2002).

8. Buhaug, H. \& Urdal, H. An urbanization bomb? Population growth and social disorder in cities. Glob. Environ. Change 23, 1-10 (2013).

9. Romero-Lankao, P. et al. A critical knowledge pathway to low-carbon, sustainable futures: integrated understanding of urbanization, urban areas and carbon. Earths Future n/a-n/a (2014). doi:10.1002/2014EF000258

10. Cities Alive | Arup Foresight.

11. Marcotullio, P. J. et al. Urbanization and the carbon cycle: Contributions from social science. Earths Future n/a-n/a (2014). doi:10.1002/2014EF000257

12. Shove, E. Beyond the ABC: climate change policy and theories of social change. Environ. Plan. A 42, 1273-1285 (2010).

13. Grimm, N. B. et al. Global change and the ecology of cities. Science 319, 756-760 (2008).

14. Braimoh, A. K. \& Onishi, T. Spatial determinants of urban land use change in Lagos, Nigeria. Land Use Policy 24, 502-515 (2007).

15. Smith, A. \& Stirling, A. The politics of social-ecological resilience and sustainable socio-technical transitions. Ecol. Soc. 15, 11 (2010).

16. Falkenmark, M. Growing water scarcity in agriculture: future challenge to global water security. Philos. Trans. R. Soc. Lond. Math. Phys. Eng. Sci. 371, 20120410 (2013).

17.*Paton, F. L., Dandy, G. C. \& Maier, H. R. Integrated framework for assessing urban water supply security of systems with non-traditional sources under climate change. Environ. Model. Softw. 60, 302-319 (2014). 
This is one of the few papers suggesting an integrated framework for assessing the security of urban water supply systems with non-traditional sources under climate change. The framework is applied to a case study in southern Adelaide.

18. Hendrix, C. S. \& Salehyan, I. Climate change, rainfall, and social conflict in Africa. J. Peace Res. 49, $35-50$ (2012).

19. *Thapa, B., Varady, R. \& Scott, C. Measuring Water Security: An Assessment of the 2013 Asian Development Bank Outlook National Water Security Index. Environ. Sci. 36-42 (2014).

The authors discuss the methodology and indicators used in the formulation of the National Water

Security Index. They evaluate its ability to quantify water security in the context of analogous indices.

20. Scott, C. A. et al. Water security and adaptive management in the arid Americas. Ann. Assoc. Am. Geogr. 103, 280-289 (2013).

21. Campbell, S. D. Sustainable development and social justice: Conflicting urgencies and the search for common ground in urban and regional planning. Mich. J. Sustain. 1, (2013).

22. Rasmussen, R. et al. Climate change impacts on the water balance of the Colorado Headwaters: Highresolution regional climate model simulations. J. Hydrometeorol. 15, 1091-1116 (2014).

23. Archer, M. S. Routine, Reflexivity, and Realism*. Sociol. Theory 28, 272-303 (2010).

24. Manuel-Navarrete, D., Pelling, M. \& Redclift, M. Critical adaptation to hurricanes in the Mexican Caribbean: Development visions, governance structures, and coping strategies. Glob. Environ. Change 21, 249-258 (2011).

25. Rutherford, J. \& Coutard, O. Urban energy transitions: places, processes and politics of sociotechnical change. Urban Stud. 51, 1353-1377 (2014).

26. Pelling, M. \& Dill, K. Disaster politics: tipping points for change in the adaptation of sociopolitical regimes. Prog. Hum. Geogr. (2009).

27. Romero-Lankao, P. \& Gnatz, D. M. Exploring urban transformations in Latin America. Curr. Opin. Environ. Sustain. 5, 358-367 (2013).

28. Grey, D. \& Sadoff, C. W. Sink or swim? Water security for growth and development. Water Policy $\mathbf{9}$, 545-571 (2007).

29. Falkenmark, M., Lundqvist, J. \& Widstrand, C. Macro-scale water scarcity requires micro-scale

approaches. in 13, 258-267 (Wiley Online Library, 1989).

30. Falkenmark, M. et al. On the verge of a new water scarcity: A call for good governance and human ingenuity. (Stockholm International Water Institute (SIWI), 2007).

31. Sullivan, C., Meigh, J. \& Lawrence, P. Application of the water poverty index at different scales: a cautionary tale. Water Int. 31, 412-426 (2006).

32. Sullivan, C. Calculating a water poverty index. World Dev. 30, 1195-1210 (2002).

33. Chaves, H. M. \& Alipaz, S. An integrated indicator based on basin hydrology, environment, life, and policy: the watershed sustainability index. Water Resour. Manag. 21, 883-895 (2007).

34. Ahern, J. From fail-safe to safe-to-fail: Sustainability and resilience in the new urban world. Landsc. Urban Plan. 100, 341-343 (2011).

35. Grothmann, T., Grecksch, K., Winges, M. \& Siebenhüner, B. Assessing institutional capacities to adapt to climate change: integrating psychological dimensions in the Adaptive Capacity Wheel. Nat. Hazards Earth Syst. Sci. 13, 3369-3384 (2013).

36. Gupta, J. et al. The adaptive capacity wheel: a method to assess the inherent characteristics of institutions to enable the adaptive capacity of society. Environ. Sci. Policy 13, 459-471 (2010).

37. Polsky, C., Neff, R. \& Yarnal, B. Building comparable global change vulnerability assessments: the vulnerability scoping diagram. Glob. Environ. Change 17, 472-485 (2007). 
38. Allouche, J. The sustainability and resilience of global water and food systems: Political analysis of the interplay between security, resource scarcity, political systems and global trade. Food Policy 36, S3-S8 (2011).

39. Filmer, D. \& Pritchett, L. H. Estimating wealth effects without expenditure Data-Or tears: An application to educational enrollments in states of india*. Demography 38, 115-132 (2001).

40. Vincent, K. Uncertainty in adaptive capacity and the importance of scale. Glob. Environ. Change 17, 12-24 (2007).

41. Eakin, H. \& Bojorquez-Tapia, L. A. Insights into the composition of household vulnerability from multicriteria decision analysis. Glob. Environ. Change 18, 112-127 (2008).

42. Romero-Lankao, P., Gnatz, D. M. \& Sperling, J. Examining Urban Inequality and Vulnerability to Enhance Resilience: Insights from Mumbai, India. Climtatic Change (2016).

43. * Jepson, W. Measuring 'no-win' waterscapes: Experience-based scales and classification approaches to assess household water security in colonias on the US-Mexico border. Geoforum 51, 107-120 (2014). This paper discusses existing metrics to measure water security. The author develops a household water security measurement for low-income peri-urban and rural communities.

44. Aceves-Quesada, J. F., Díaz-Salgado, J. \& López-Blanco, J. Vulnerability assessment in a volcanic risk evaluation in Central Mexico through a multi-criteria-GIS approach. Nat. Hazards 40, 339-356 (2007).

45. De Maio, F. G. Income inequality measures. J. Epidemiol. Community Health 61, 849-852 (2007).

Table 1: Indicators that can be used to assess SETEG domains of urban water security

\begin{tabular}{|l|l|}
\hline Domain & Sustainability and/or Resilience Indicator \\
\hline Sociodemographic & $\begin{array}{l}\text { Access to improved piped water supply } \\
\text { Access to improved sanitation } \\
\text { Diarrhea incidence per 100,000 people } \\
\text { Population density, age, gender, education }\end{array}$ \\
\hline$\underline{\text { Economic }}$ & $\begin{array}{l}\text { Competing water demands/consumption rates } \\
\text { Dependence on imported water } \\
\text { Gini index }\end{array}$ \\
\hline Technological & $\begin{array}{l}\text { Built-environment: density } \\
\text { Water infrastructure development } \\
\text { Reliability, Maximum duration of failure and of annual vulnerability }\end{array}$ \\
\hline$\underline{E}$ nvironmental & $\begin{array}{l}\text { Watershed land uses (disturbance) } \\
\text { Urban surface growth rate vs river or water body health }\end{array}$ \\
\hline$\underline{\text { Governance }}$ & $\begin{array}{l}\text { Land use zoning, building codes, growth caps, hazard (e.g., floodplain) } \\
\text { maps, } \\
\text { Networks, legal frameworks, information }\end{array}$ \\
\hline
\end{tabular}

Based on 19,29-33-37-38. 


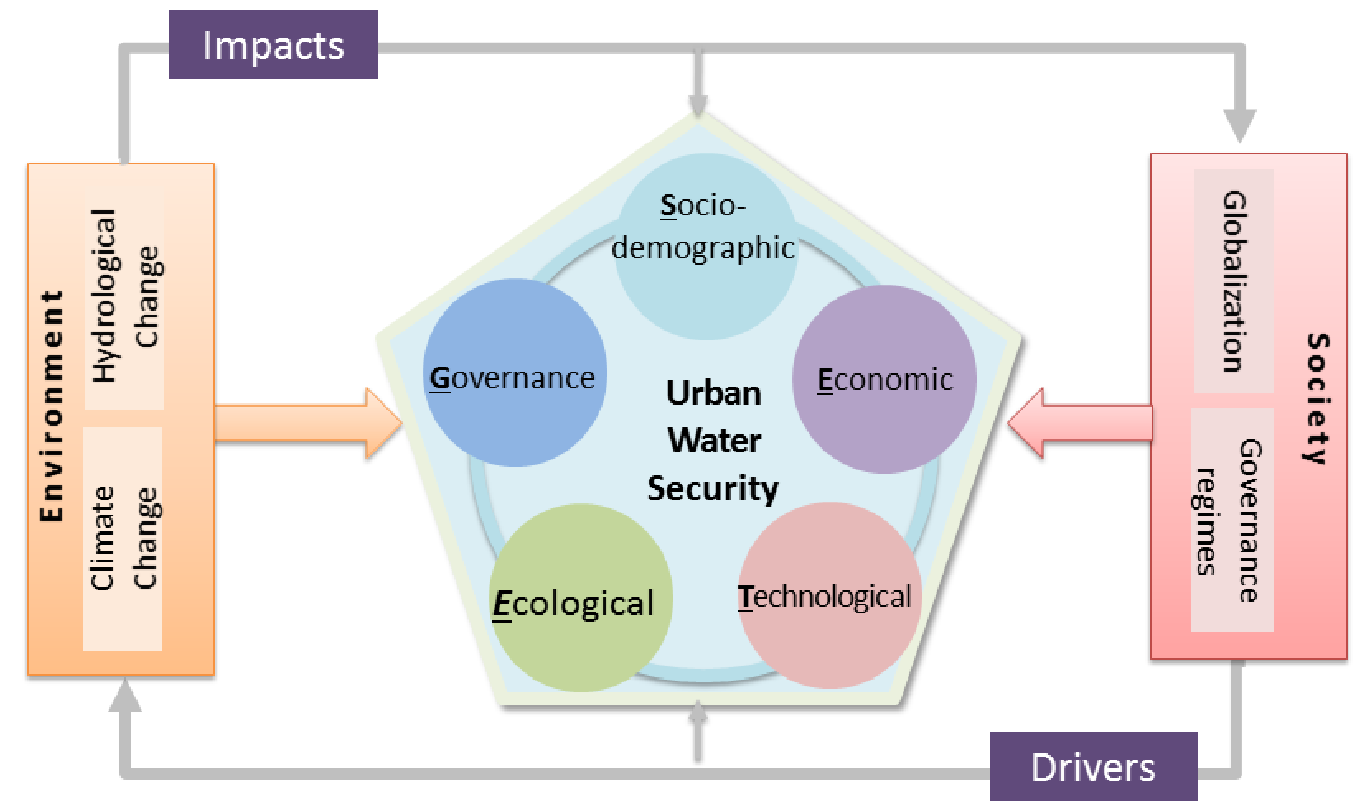

Figure 1: Urban Water Security. This conceptual diagram shows urban water security as a product of five interacting development domains, which also interact with environmental dynamics: Socio-demographic, Economic, Technological, Ecological, and Governance. These domains operate within a wider context of interactions between environment and society. 


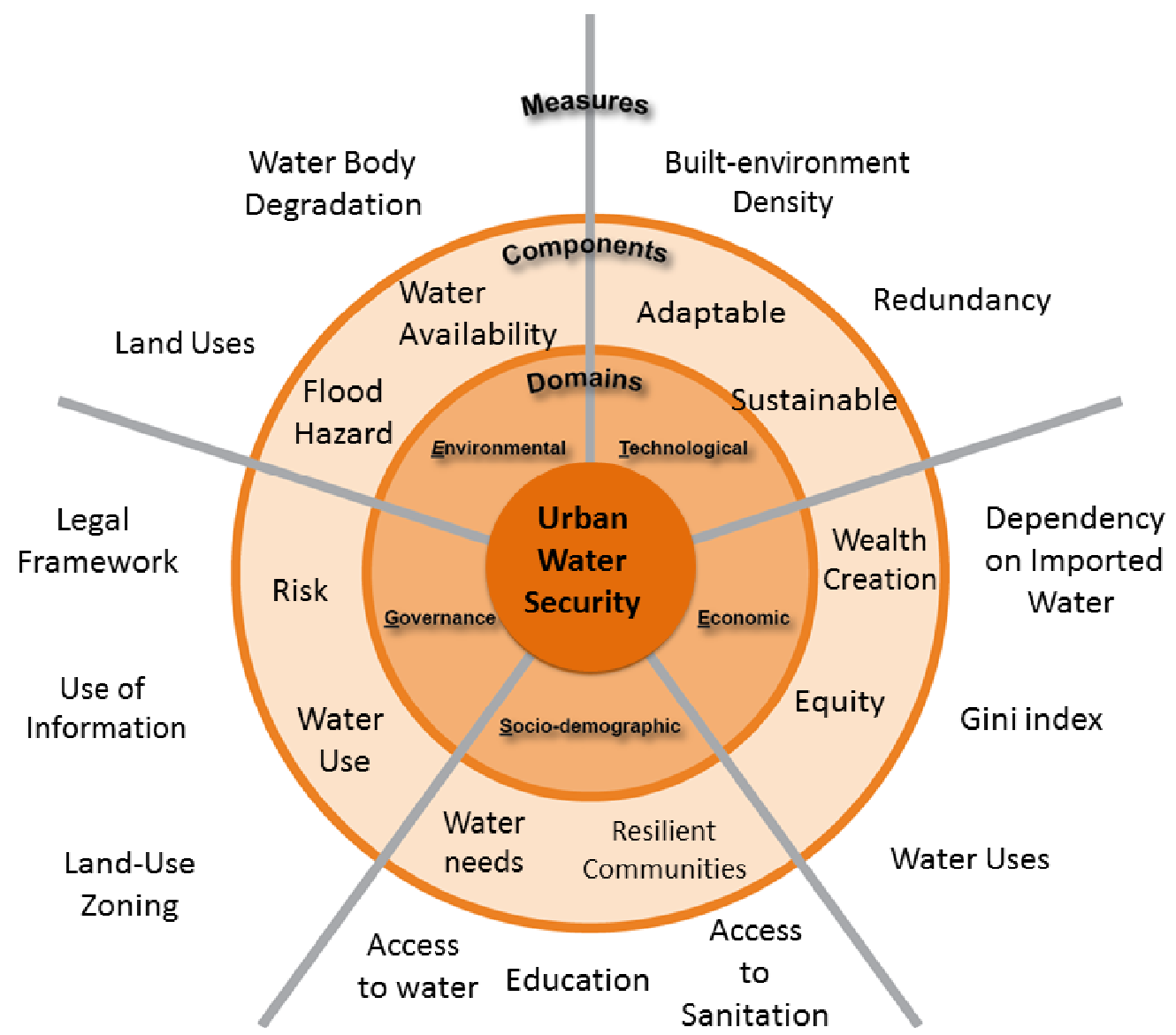

Figure 2: Urban Water Security, Scoping Diagram 